\title{
Valence Level Character in a Mixed Perovskite Material and Determination of the Valence Band Maximum from Photoelectron Spectroscopy: Variation with Photon Energy
}

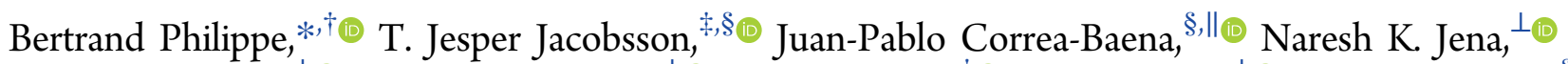

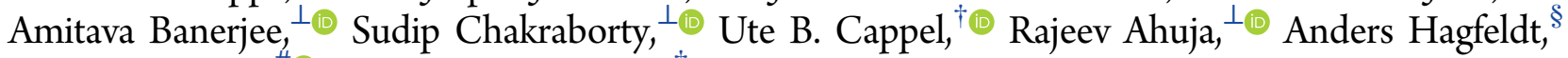 \\ Michael Odelius, ${ }^{\oplus}$ and Håkan Rensmo* ${ }^{*}{ }^{\dagger}$

\footnotetext{
${ }^{\dagger}$ Molecular and Condensed Matter Physics, Department of Physics and Astronomy, Uppsala University, Box 516, 75120 Uppsala, Sweden

${ }^{\ddagger}$ Department of Chemistry-Ångström Laboratory, Uppsala University, Box 523, 75121 Uppsala, Sweden CH-1015-Lausanne, Switzerland

"Massachusetts Institute of Technology, Cambridge, Massachusetts 02139, United States

${ }^{\perp}$ Materials Theory Division, Department of Physics and Astronomy, Uppsala University, Box 516, 75120 Uppsala, Sweden

\# Department of Physics, AlbaNova University Center, Stockholm University, 10691 Stockholm, Sweden
} \\ ${ }^{\S}$ Laboratory for Photomolecular Science, Institute of Chemical Sciences and Engineering, École Polytechnique Fédérale de Lausanne,
}

\section{Supporting Information}

\begin{abstract}
A better understanding of the electronic structure of perovskite materials used in photovoltaic devices is essential for their development and optimization. In this investigation, synchrotron-based photoelectron spectroscopy (PES) was used to experimentally delineate the character and energy position of the valence band structures of a mixed perovskite. The valence band was measured using PES with photon energies ranging from ultraviolet photoelectron spectroscopy $(21.2 \mathrm{eV})$ to hard X-rays (up to $4000 \mathrm{eV}$ ), and by taking the variation of the photoionization cross sections into account, we could experimentally determine the inorganic and organic contributions. The experiments were compared to theoretical calculations to further distinguish the role of the different anions in the electronic structure. This work also includes a thorough study of the valence band maximum and its position in relation to the Fermi level, which is crucial for the design and optimization of complete solar cells and their functional properties.
\end{abstract}

\section{INTRODUCTION}

The replacement of fossil fuels is an environmental obligation, and to limit greenhouse gas emission there is an urgent need to develop the use of renewable energy. Among the available technologies, solar energy is probably the most attractive. Solar cells are based on the conversion of energy from sunlight into electricity. A wide range of materials can fulfill this conversion with varying performance, cost, and characteristics suitable for different potential applications. ${ }^{1,2}$

Perovskite solar cells (PSCs) have emerged recently and are outperforming most other emerging solar cell technologies in terms of power conversion efficiency. The breakthrough was initiated by using methylammonium lead tri-iodide $\left(\mathrm{CH}_{3} \mathrm{NH}_{3} \mathrm{PbI}_{3}\right)$ as a photoabsorber in a dye-sensitized solar cell (DSSC)-like structure. ${ }^{3}$ Today perovskite solar cells are often constituted of a thin polycrystalline perovskite layer of a few hundred nanometers sandwiched between charge-selective contacts. Over the past few years, the continuous development of the perovskite materials; of the deposition process; ${ }^{4,5}$ and of the other constituents of the solar cell devices, i.e. hole and electron transport materials, ${ }^{6-9}$ has allowed an impressive improvement in performance and stability. This has raised the power conversion efficiency of perovskite solar cells from $3.8 \%$ in the initial work in 2009 to a certified efficiency of $22.1 \%$ in 2016. ${ }^{10,11}$ The highest efficiencies reported to date in the literature have been obtained by perovskites with the general formula $\mathrm{AMX}_{3}$ where $\mathrm{A}$ is a mixture of the cations methylammonium $\left(\mathrm{CH}_{3} \mathrm{NH}_{3}{ }^{+}, \mathrm{MA}\right)$ and formamidinium $\left(\mathrm{CH}_{3}\left(\mathrm{NH}_{2}\right)_{2}{ }^{+}, \mathrm{FA}\right)$, and potentially also $\mathrm{Cs}^{+}$and/or $\mathrm{Rb}^{+} ; \mathrm{M}$ is the $\mathrm{Pb}^{2+}$ ion; and $\mathrm{X}$ is a mixture of halides, i.e., $\mathrm{I}^{-}$and $\mathrm{Br}^{-}{ }^{-12}$ Not only the performance but also the stability of these materials has recently been improved making these materials more viable for commercialization. ${ }^{13,14}$

Received: September 8, 2017

Revised: November 13, 2017

Published: November 14, 2017 
Understanding the atomic and electronic structure of perovskites and their interfaces is important for further improvement of the material properties, such as interfacial chemistry, band gap, and band gap states, as well as the positions of the conduction and valence band edges. ${ }^{15-17}$ Among the different experimental techniques, photoemission spectroscopy, also referred to as photoelectron spectroscopy (PES), can provide unique information at an atomic level on the chemistry at interfaces.

In solar-cell research, ultraviolet photoelectron spectroscopy (UPS, $h \nu=21.2$ or $40.8 \mathrm{eV}$, i.e., $\mathrm{He} \mathrm{I}$ and $\mathrm{He}$ II lines, respectively) is frequently used to obtain information on the density of states and also to construct energy level diagrams for combinations of materials in solar cell devices. The construction of these diagrams requires the determination of the work function of a material as well as the position of the valence band maximum (VBM) or highest occupied molecular orbital level versus the Fermi or vacuum level. Such information is crucial in the design of a complete solar cell where the energy matching between the various components will influence the overall performance. Although X-ray photoelectron spectroscopy (XPS, $h \nu=1486.6 \mathrm{eV}$ or $1253.7 \mathrm{eV}$ ) and by extension, synchrotron-based PES such as SOXPES $(h \nu<1500 \mathrm{eV})$ and HAXPES $(h \nu>2 \mathrm{keV})$, can be used in the same way, these techniques are more commonly used in investigations of the properties of the separate materials through their core level peaks including chemical composition (quantitative and qualitative).

While studies employing a single photon energy (such as UPS and XPS) are common, measuring valence spectra at a range of photon energies can give additional information. There are, however, several aspects to take into consideration when going from a few electronvolts to several kiloelectronvolts and when comparing the results and spectra obtained: (1) The evolution of the inelastic mean free path (IMFP) of the emitted electrons, which increases when their kinetic energy increases, and as a consequence the contributions from different probing depths. Changes of the photon energy thus allow for a variation of the analysis depth from a few angströms to several nanometers and open the possibility to investigate either the outermost layer or more bulk-like properties. (2) The use of different photon energies also affects the photoionization cross sections $(\sigma)$ with values available for different core levels and often estimated from theoretical predictions of atoms. In the valence levels, cross sections may be approximated from the orbital composition and hybridization together with the individual atomic cross sections. As a consequence, it is possible to exacerbate the contribution of some specific atomic orbitals by selecting a photon energy where the cross sections for a specific component is maximized compared to others.

Experimental insights into the detailed electronic structure are of importance for developing a better understanding of the PSCs. In our previous work, we investigated the core level peaks of state-of-the-art perovskites with the emphasis on the surface chemical composition and using quantification considerations. $^{18}$

In this work, we delve deeper into the possibility of varying the photon energy in the PES measurements to experimentally delineate the character of the valence levels in the material. We describe also how the determination of the VBM is influenced by the photon energy used and as a consequence by the techniques employed to estimate it. We present PES data on a hybrid organic-inorganic perovskite material with special attention given to the valence band spectra using different photon energies going from 21.2 to $4000 \mathrm{eV}$. The perovskite material selected, in our case $\left(\mathrm{MA}_{0.15} \mathrm{FA}_{0.85} \mathrm{~Pb}\left(\mathrm{I}_{0.85} \mathrm{Br}_{0.15}\right)_{3}\right)$, is one of the best performing compositions and thus a highly relevant material to investigate in detail. It is composed of both cation and anion mixtures and referred to as "mixed perovskite" in the rest of the paper. ${ }^{11,19,20}$ Similarly efficient PSCs have been made with the addition of small amounts of $\mathrm{Cs}^{21}$ and/or $\mathrm{Rb}^{22,23}$ Supporting calculations based on density function theory (DFT) were also performed, which assist in the assignment of spectral features and help rationalize the photon energy dependence in PES. The main objectives of the calculations were to give chemical insight into how the molecular orbitals (hybridization) are generated and to support the experimental findings. For this purpose, two simpler model systems, $\mathrm{MAPbI}_{3}$ and $\mathrm{MAPbBr}_{3}$, were used which allowed us to give a general interpretation of the valence level structure of the mixed perovskite material.

\section{EXPERIMENTAL AND THEORETICAL METHODS}

2.1. Material Preparation. The perovskite material investigated in this work was prepared in line with a previous work in which a detailed material preparation protocol can be found. ${ }^{18}$ The sample is composed of fluorine-doped tin oxide (FTO), a compact $\mathrm{TiO}_{2}$-layer, a mesoporous layer of $\mathrm{TiO}_{2}$, and a mixed perovskite deposited by spin coating using a one-step antisolvent method. The perovskite material is composed of both cation and anion mixtures: $\mathrm{MA}_{0.15} \mathrm{FA}_{0.85} \mathrm{~Pb}\left(\mathrm{I}_{0.85} \mathrm{Br}_{0.15}\right)_{3}$. In addition to a so-called stoichiometric material, two other mixed perovskites were prepared based on a nonstoichiometric precursor solution containing either excess or a deficiency of $\mathrm{PbI}_{2}$. Most of the results shown in the main part of the current paper will refer to the sample with $\mathrm{PbI}_{2}$ excess, as this composition showed the most homogeneous surfaces and gave solar cells with the best performance. ${ }^{19,20}$ In short, for the material reported here, the mixed perovskite was prepared by mixing 0.22 $\mathrm{M} \mathrm{PbBr}_{2}, 0.22 \mathrm{M} \mathrm{MABr}$, and 1.04 $\mathrm{M} \mathrm{PbI}_{2}$, and the concentration of FAI was such that $[\mathrm{FAI}]=0.9\left[\mathrm{PbI}_{2}\right]$.

After preparation of the perovskite materials, the samples were stored in a sealed box together with common desiccants to avoid any influence of moisture. The box was opened only prior to the PES analysis, and the samples were quickly introduced into the vacuum chamber after less than 5 min in air after being placed on the sample holder.

2.2. Photoelectron Spectroscopy. Photoelectron spectroscopy measurements were performed at two different synchrotron facilities with two complementary photon energy ranges.

Hard X-ray PES (HAXPES) was carried out at BESSY II (Helmholtz Zentrum Berlin, Germany) at the KMC-1 beamline $^{24}$ using the HIKE end-station. ${ }^{25}$ The end-station is provided with a usable photon energy range from 2 to $12 \mathrm{keV}$; the photon energy is selected using a double-crystal monochromator (Oxford-Danfysik), and the photoelectron kinetic energies (KE) were measured using a Model R4000 analyzer (Scienta) optimized for high kinetic energies. In this work, photon energies of 2100 and $4000 \mathrm{eV}$ were used by selecting the first-order light from a $\mathrm{Si}(111)$ and $\mathrm{Si}(311)$ crystals, respectively. The pressure in the analysis chamber was $\sim 10^{-8}$ mbar.

Soft X-ray Photoelectron spectroscopy (SOXPES) measurements were carried out at the beamline I411 at the Swedish National Synchrotron Facility Max IV Laboratory in Lund, 

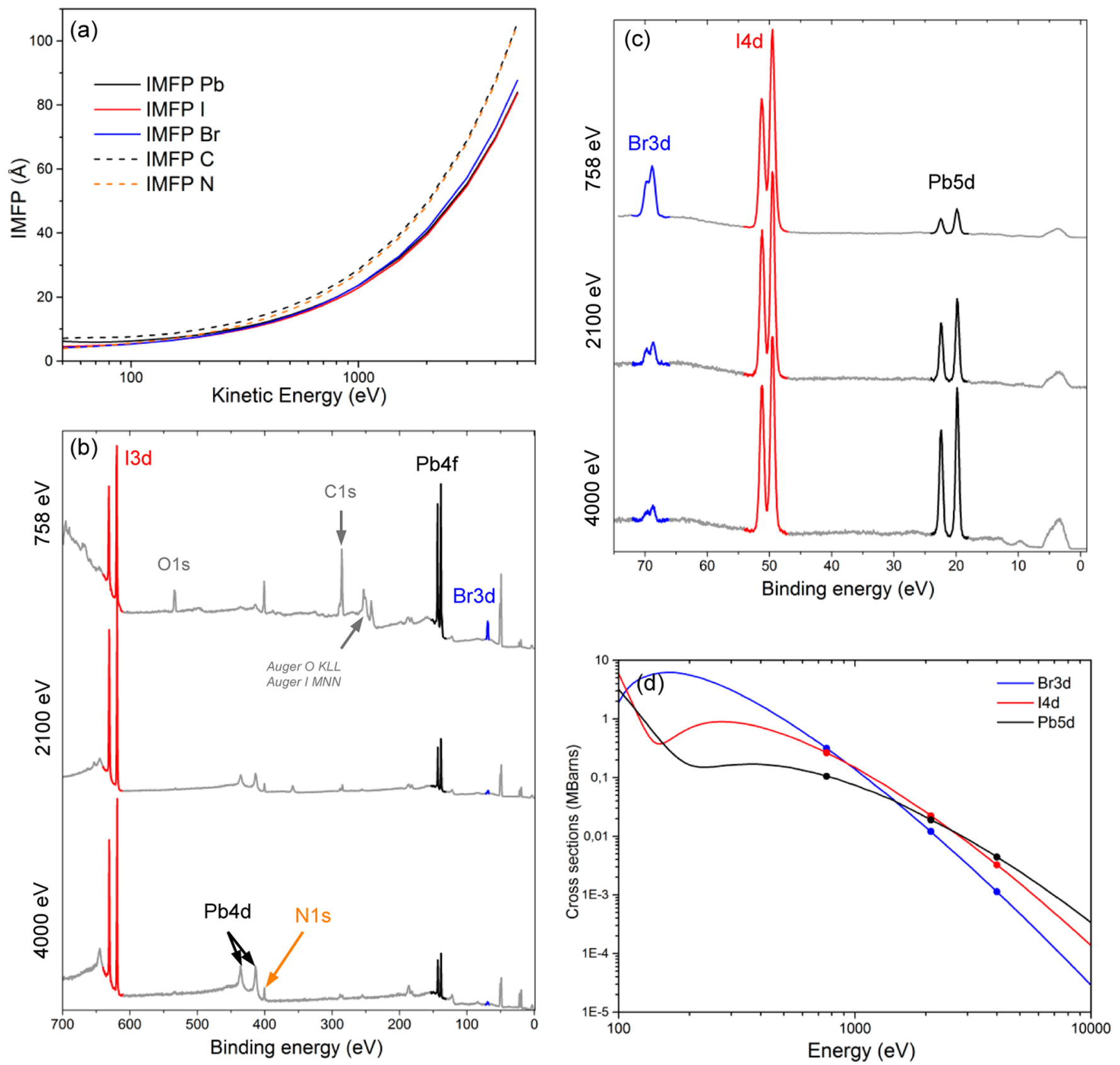

Figure 1. (a) Evolution of the inelastic mean free path (IMFP) of the element composing the mixed perovskite (i.e., $\mathrm{Pb}, \mathrm{I}, \mathrm{Br}, \mathrm{C}, \mathrm{N}$ ) as a function of the kinetic energy. These curves were plotted from IMFP values obtained using the QUASES - IMFP - TPP2M software program applying the Tanuma, Powell, and Penn (TPP-2M) algorithm (ref 16). (b) Overview spectra (700-0 eV binding energy range) of the mixed perovskite material recorded with three different photon energies: 758, 2100, and $4000 \mathrm{eV}$. (c) PES spectra (75-0 eV binding energy range) of the mixed perovskite material recorded with the same energies. These spectra were intensity normalized versus the I $4 \mathrm{~d}$ core level peak. (d) Evolution of the photoionization cross sections of $\mathrm{I} 4 \mathrm{~d}, \mathrm{~Pb} 5 \mathrm{~d}$, and $\mathrm{Br} 3 \mathrm{~d}$ (see Experimental and Theoretical Methods).

Sweden. The end-station was in this case provided with a usable photon energy range from 50 to $1500 \mathrm{eV}$. The photon energies were selected using a modified Zeiss SX-700 monochromator, and the photoelectron kinetic energies (KE) were measured using a Scienta R4000 WAL analyzer. The pressure in the analysis chamber was $\sim 10^{-8}$ mbar. Measurements with photon energies of $80,250,500$, and $758 \mathrm{eV}$ were recorded.

Overview spectra were measured with a pass energy (Ep) of $500 \mathrm{eV}$, while $200 \mathrm{eV}$ was used for core peaks and valence band spectra. The HAXPES spectra presented in this work were energy calibrated versus the Fermi level at zero binding energy, which was determined by measuring a gold plate in electric contact with the sample and setting the $\mathrm{Au} 4 \mathrm{f}_{7 / 2}$ core level peak to $84.0 \mathrm{eV}$. On the basis of this measurement, the overall resolution was better than $0.5 \mathrm{eV}$. The SOXPES spectra were energy aligned to the HAXPES spectra using the $\mathrm{Pb} 5 \mathrm{~d}_{5 / 2}$ core level peak that was set to $19.82 \mathrm{eV}$.

The UPS spectrum presented in this work was performed on a PHI5000 VersaProbe and the UPS radiation was generated by a He-gas discharge lamp ( $\mathrm{He} \mathrm{I} \alpha$ at $21.22 \mathrm{eV}$ ). The UPS spectrum was energy calibrated by setting the Fermi edge of clean silver at $0 \mathrm{eV}$.

The IMFP graphs and values presented in this work were generated with the software QUASES-IMFP-TPP2M applying 
the Tanuma, Powell, and Penn (TPP-2M) algorithm. ${ }^{26}$ Finally, the photoionization cross sections were extracted from refs 27 and 28 for the $0-1500 \mathrm{eV}$ energy range and available in ref 29 , while energies above $1500 \mathrm{eV}$ were based on the Scofield database. $^{30}$

2.3. Computational Details. To assign the measured PES and to simulate the spectral dependence on the energy of the incoming photons, we use molecular orbital theory within the Kohn-Sham formulation of DFT. This allows us to combine the contribution from each atom to the electronic density of states (DOS) with the energy dependence in the photoelectron cross section for each element. The analysis is based on the partial density of states (PDOS) of each element $(\mathrm{Pb}, \mathrm{I}, \mathrm{Br}, \mathrm{C}$, $\mathrm{N}$ ) in the pure $\mathrm{MAPbI}_{3}$ and $\mathrm{MAPbBr}_{3}$ compounds, of which parts have already been presented in Figures 5 and 6 in our previous study. ${ }^{31}$ The PDOS was obtained from the KohnSham orbitals in the Quickstep program within the CP2K software suite ${ }^{32-35}$ using a dispersion-corrected BLYP functional in $\Gamma$ point calculations. ${ }^{36-39}$

Supercell $(2 \times 2 \times 2)$ models of the $\mathrm{CH}_{3} \mathrm{NH}_{3} \mathrm{PbI}_{3}(\mathrm{~s})$ and $\mathrm{CH}_{3} \mathrm{NH}_{3} \mathrm{PbBr}_{3}(\mathrm{~s})$ unit cells were calculated with $\mathrm{GTH}$ pseudopotentials $^{40-42}$ in combination (denoted GPW) with Gaussian basis sets (DZVP-GTH) ${ }^{43}$ to describe the wave function and an auxiliary plane wave basis to describe electron density. The PDOS data was convoluted by a Gaussian function with full width at half-maximum of $0.5 \mathrm{eV}$ and shifted for alignment with the experimental spectra. Further computational details can be found in our previous work. ${ }^{31}$

As a complement to the calculations of the pure $\mathrm{CH}_{3} \mathrm{NH}_{3} \mathrm{PbI}_{3}(\mathrm{~s})$ and $\mathrm{CH}_{3} \mathrm{NH}_{3} \mathrm{PbBr}_{3}(\mathrm{~s})$ compounds, we also present in the Supporting Information results from calculations of the presently investigated compound with mixed counterions and mixed halide ions. The computational approach of this calculation is described in the Supporting Inormation.

\section{RESULTS AND DISCUSSION}

The main objective of the present investigation is to experimentally characterize and interpret the valence spectra. This includes an analysis of the extended valence spectra but also an in-depth discussion of the valence band maximum (VBM). Before proceeding with the analysis of the valence levels, we will introduce the effects of photon energy variation on the core level spectra and highlight the impact of the IMFP and photoionization cross sections on the different spectra and their interpretation. These parameters will also affect the interpretation of valence level spectra.

3.1. Impact of the Photon Energy Variation on the Core Level Peaks. As mentioned in the introduction, the notion of IMFP of an emitted electron is directly linked to the surface sensitivity to the measurement. The evolution of the IMFP will be slightly different for different elements and/or materials but follows a similar general trend.

Figure 1a presents the evolution of the IMFP of the pure elements constituting our mixed perovskite, i.e., $\mathrm{Pb}, \mathrm{I}, \mathrm{Br}, \mathrm{C}$, and N. It is well-known that the IMFP increases as a function of the kinetic energy; thus, for a given core level peak, more surface information is obtained when a lower photon energy is used.

The overview spectra of our mixed perovskite recorded with 758,2100 , and $4000 \mathrm{eV}$ are presented in Figure $1 \mathrm{~b}$. The measurement at $758 \mathrm{eV}$ is the most surface sensitive among the three presented and will be the most efficient one to detect even minimal surface contamination. For example, in the overview spectra in Figure $1 \mathrm{~b}$, the $\mathrm{O} 1 \mathrm{~s}$ signal detected at a binding energy of $533 \mathrm{eV}$ with incident photons of $758 \mathrm{eV}$ arises largely from surface contamination, while it is barely observed at 2100 or $4000 \mathrm{eV}$. The same is observed regarding the contamination peak on the $\mathrm{C} 1 \mathrm{~s}$ core level peak at $285 \mathrm{eV}$ that is dominating the spectrum at $758 \mathrm{eV}$, whereas the $\mathrm{MA}^{+}$ and $\mathrm{FA}^{+}$cation contributions at 286.7 and $288.7 \mathrm{eV}$, respectively, can be more clearly observed for $4000 \mathrm{eV}$ (Figure S1).

The influence of the IMFP should not be neglected, and it is important to remember that the signal from the various core levels of a given element have different IMFPs, as the kinetic energy of the photoelectron is different. The iodine core levels I $3 \mathrm{~d}$ and $\mathrm{I} 4 \mathrm{~d}$ recorded with a photon energy of $758 \mathrm{eV}$, for example, have an IMFP of 6 and $17 \AA$, respectively. This difference can be of great importance when a sample is not homogeneous and can easily lead to misinterpretation when directly translating core level information into atomic percentages. These differences can be limited by comparing core levels located in a narrow binding energy region, i.e., photoelectrons with a similar kinetic energy and as a consequence similar IMFP. The binding energy region presented in Figure 1c contains the core level peaks Br 3d, I $4 \mathrm{~d}$, and $\mathrm{Pb} 5 \mathrm{~d}$, and quantifications in our previous work were done using their intensities. ${ }^{18}$ On the basis of the same argument, we can assume that the information contained in a valence band is made of electrons all originating from a similar surface sensitivity.

When comparing the spectra of Figure 1c, clear intensity differences between $\mathrm{Br} 3 \mathrm{~d}, \mathrm{I} 4 \mathrm{~d}$, and $\mathrm{Pb} 5 \mathrm{~d}$ can be observed. These differences are directly related not only to the proportion of the elements present in the material but also to different photoionization cross sections $(\sigma)$. Quantification can be made only after correction by these parameters. The evolution of the ionization cross sections of $\mathrm{Br} 3 \mathrm{~d}, \mathrm{I} 4 \mathrm{~d}$, and $\mathrm{Pb} 5 \mathrm{~d}$ is presented in Figure $1 \mathrm{~d}$ as a function of the photon energy. The evolution of the cross section of the main core level peaks observed in the overview spectra can also be found in Figure S2. The cross sections of the elements presented in Figure 1d are all decreasing when the excitation energy increases. However, if we look at the detailed variation of these curves, we can see that at $758 \mathrm{eV}, \sigma_{\mathrm{Br} 3 \mathrm{~d}}>\sigma_{\mathrm{Pb} 5 \mathrm{~d}}$ but at $4000 \mathrm{eV}, \sigma_{\mathrm{Br} 3 \mathrm{~d}}<\sigma_{\mathrm{Pb} 5 \mathrm{~d}}$. These changes are directly observed in the PES spectra, as the intensity peak of $\mathrm{Pb} 5 \mathrm{~d}$ gets significantly stronger compared to the $\mathrm{Br} 3 \mathrm{~d}$ core level peak when the photon energy increases.

The calculated $\mathrm{I} / \mathrm{Pb}$ and $\mathrm{Br} / \mathrm{Pb}$ ratio measured with three different photon energies are presented in Table 1 and are seen to vary with probing depth. This is in line with our earlier reports based on similar quantitative estimations that the mixed perovskites are not always perfectly homogeneous toward the surface. We showed that the bulk ratios obtained by using

Table 1. Intensity Ratios between Different Core Levels Calculated from Experimental Results as a Function of the Excitation Energy $(4000,2100 \text {, and } 758 \mathrm{eV})^{a}$

$\begin{array}{cccc}\mathrm{h} \nu(\mathrm{eV}) & \text { probing depth }[\mathrm{nm}] & \mathrm{I} / \mathrm{Pb} & \mathrm{Br} / \mathrm{Pb} \\ 758 & 5 & 3.82 & 0.80 \\ 2100 & 11 & 2.90 & 0.53 \\ 4000 & 18 & 2.28 & 0.45\end{array}$

${ }^{a}$ Adapted from ref 18 . The theoretical $\mathrm{I} / \mathrm{Pb}$ and $\mathrm{Br} / \mathrm{Pb}$ ratio, based on the precursor solution, are 2.4 and 0.52 , respectively. 
theoretical cross sections are relatively close to the stoichiometry expected from the precursor solution used while the surface contains some extra iodide explaining the high $\mathrm{I} / \mathrm{Pb}$ ratio observed for $758 \mathrm{eV} .^{18,44}$

These results highlight the advantage of the variation in surface sensitivity with photon energy or more specifically with the kinetic energy of the elastically emitted photoelectrons and how core levels can be used to get a better insight about the composition of a sample. Nevertheless, it is important to have a good control of the cross sections, and although such corrections are maybe obvious and expected when considering core level regions, it is important to remember that the same considerations should be taken in the valence region.

3.2. Impact of the Photon Energy Variation on the Valence Band Spectra. Photoelectron spectroscopy is mainly used in the solar-cell community to investigate the energies directly linked to the optoelectronic properties of perovskite materials and in particular the position of the VBM compared to the Fermi level. In the following, the valence band spectra will be investigated as a function of the excitation energy, ranging from $21.2 \mathrm{eV}$ used in UPS to $4000 \mathrm{eV}$ used in HAXPES.

Figure $2 \mathrm{a}$ presents an extended view of the valence band measured with seven different photon energies: 21.2, 80, 250, 500, 758, 2100, and $4000 \mathrm{eV}$. All spectra (except for the UPS spectrum at $21.2 \mathrm{eV}$ ) contain two sharp peaks at 19.8 and 22.4 $\mathrm{eV}$ corresponding to $\mathrm{Pb} 5 \mathrm{~d}_{5 / 2}$ and $\mathrm{Pb} 5 \mathrm{~d}_{3 / 2}$, respectively, and assigned to $\mathrm{P} \mathrm{Pb}^{2+}$ oxidation state. At a binding energy of 18.0 $\mathrm{eV}$, a minor peak is observed (marked by a red arrow in Figure 2a) and is assigned to $\mathrm{Pb} 5 \mathrm{~d}_{5 / 2}$ for the metallic lead $\mathrm{Pb}^{0}(<1$ atom \%). The effect of $\mathrm{Pb}^{0}$ in solar cell devices is still not completely clear. ${ }^{45,46}$ However, its presence is useful in this present PES study to control the viability of the Fermi level energy calibration procedure used. The position of $\mathrm{Pb}^{0}$ can thus be used as an internal reference, and the fact that its binding energy is at $18.0 \mathrm{eV}$, as generally referenced for metallic lead, validates the energy calibration and indicates that charging effects are negligible.

The lower binding energy region of the spectra $(17-0 \mathrm{eV})$ is dominated by valence state structures arising from different hybridizations mixing the frontier atomic states. These structures will be described in detail in the next section of the paper, but we can already mention that they contain the valence electrons of our mixed perovskite, i.e., $\mathrm{Pb}(6 \mathrm{~s}, 6 \mathrm{p})$, I $(5 s, 5 p), B r(4 s, 4 p), C 2 p$, and N 2p. When the photon energy is varied, the evolution of the $\mathrm{Pb} 5 \mathrm{~d}$ core level peaks compared to the rest of the valence band structure can be directly related to the evolution of their relative cross sections shown in Figure $2 \mathrm{~b}$. The $\mathrm{Pb} 5 \mathrm{~d}$ core levels mainly dominate all the spectra, whereas the valence structures are quite weak except when a photon energy of $250 \mathrm{eV}$ is used. The cross section of $\mathrm{Pb} 5 \mathrm{~d}$ at $80 \mathrm{eV}$ is about 2 orders of magnitude higher than the cross sections of levels dominating other parts of the valence structure (Figure 2b). At $250 \mathrm{eV}$, this difference in cross sections reaches a minimum and increases again from 250 to $4000 \mathrm{eV}$, explaining also the experimentally observed evolution.

When the evolution of the photoionization cross sections of the valence electrons (i.e., excluding $\mathrm{Pb} 5 \mathrm{~d}$ ) are compared, it is clear that the relative cross section between the elements in the $\mathrm{MA}^{+}$and $\mathrm{FA}^{+}$cations (i.e., carbon and nitrogen) versus those of the $\left[\mathrm{PbX}_{6}\right]^{-}$octahedral (including I $5 \mathrm{p} / \mathrm{s}$ and $\mathrm{Br} 4 \mathrm{p} / \mathrm{s}$ ) vary in a different manner depending on the excitation used. At $80 \mathrm{eV}$ excitation energy, the cross sections are higher for $\mathrm{C} 2 \mathrm{p}$ or $\mathrm{N} 2 \mathrm{p}$
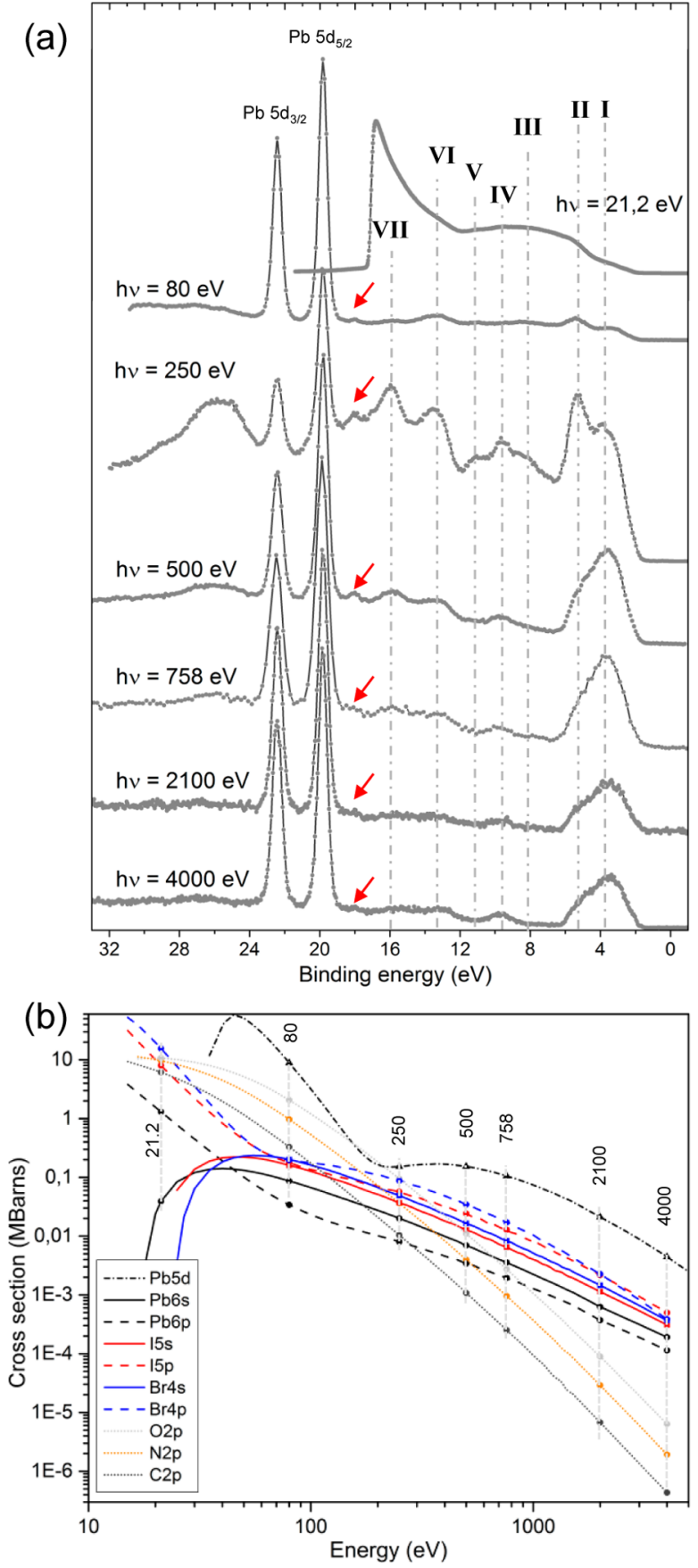

Figure 2. (a) Evolution of the valence band spectra, including the $\mathrm{Pb}$ 5d core level, of the mixed perovskite material as a function of the photon energy. The spectra were recorded with seven different energies: $21.2,80,250,500,758,2100$, and $4000 \mathrm{eV}$. The red arrows indicate the metallic lead $\left(\mathrm{Pb}^{0}\right)$ component in the $\mathrm{Pb} 5 \mathrm{~d}$ core level peak. (b) Evolution of the photoionization cross section of the main valence electrons of $\mathrm{Pb}(5 \mathrm{~d}, 6 \mathrm{~s}, 6 \mathrm{p}), \mathrm{I}(5 \mathrm{~s}, 5 \mathrm{p}), \mathrm{Br}(4 \mathrm{~s}, 4 \mathrm{p}), \mathrm{O} 2 \mathrm{p}, \mathrm{N}$ $2 p$, and $C 2 p$ as a function of the energy in electronvolts. The photon energies used in this work are highlighted with vertical gray lines.

(i.e., $\mathrm{MA}^{+}$and $\mathrm{FA}^{+}$constituents) than for the I $5 \mathrm{p} / \mathrm{s}$ and $\mathrm{Br} 4 \mathrm{p} /$ $\mathrm{s}$, while the opposite is observed for photon energies higher than $500 \mathrm{eV}$. The cross-sectional variation will have an impact on the experimental spectra, and we can already predict that the organic part of our materials will be easily observed in the valence band when low photon energies are used, while the 
inorganic part should dominate the spectra at higher energies $(>500 \mathrm{eV})$.

To give a more detailed description and discussion of the valence band structures, DFT calculations are a valuable support to define and attribute more accurately the valence band structures numbered I-VII in Figure 2a.

3.2.1. Interpretation of the Valence Structure. DFT calculations on $\mathrm{CH}_{3} \mathrm{NH}_{3} \mathrm{PbI}_{3}$ and $\mathrm{CH}_{3} \mathrm{NH}_{3} \mathrm{PbBr}_{3}$ models were used as a basis to assign the main structures observed experimentally in our valence band and to rationalize the photon energy dependence in the experimental valence band spectra. Figure 3 shows the total density of states (TDOS) and

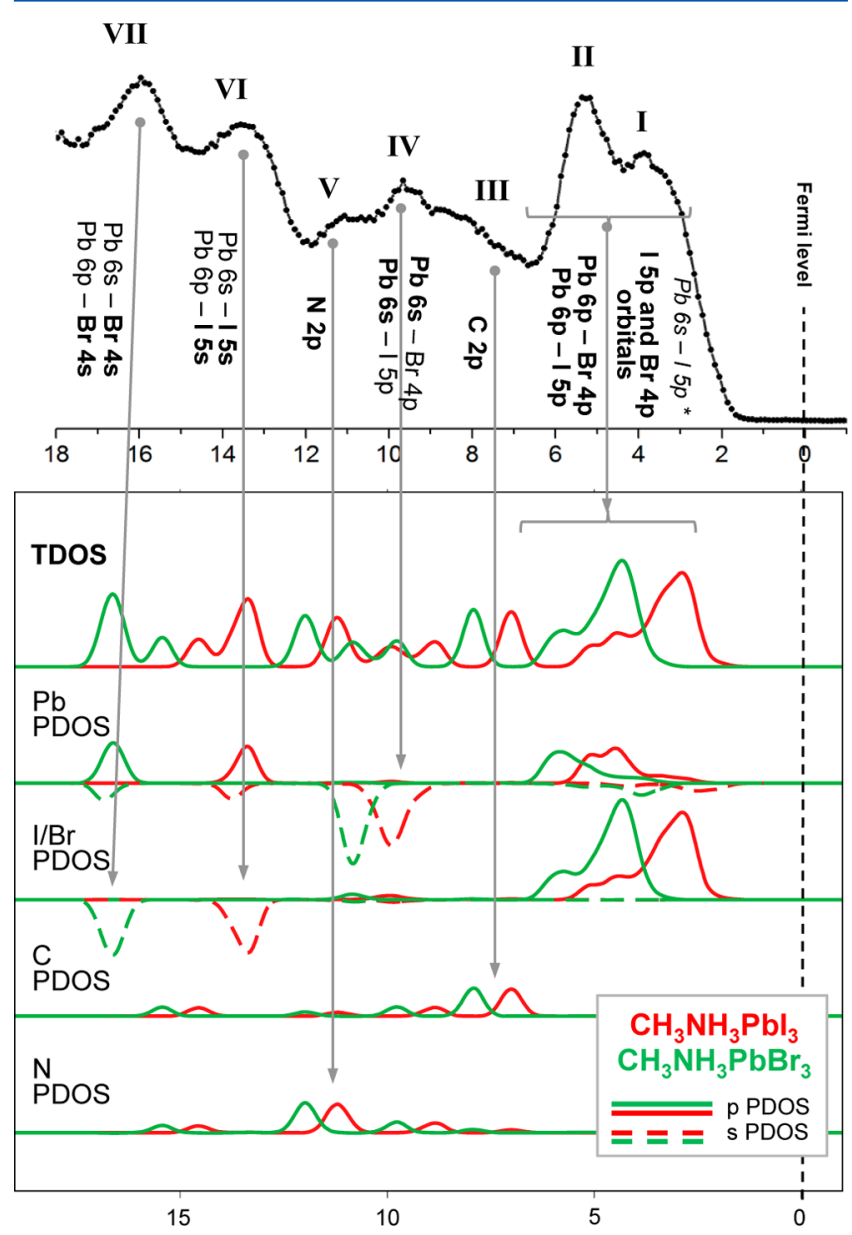

Figure 3. Total density of states (TDOS) of the $\mathrm{CH}_{3} \mathrm{NH}_{3} \mathrm{PbI}_{3}$ and $\mathrm{CH}_{3} \mathrm{NH}_{3} \mathrm{PbBr}_{3}$ models decomposed into partial density of states (PDOS) of each element. The calculated spectra are decomposed into $\mathrm{s}$ - and p-character, in dashed and solid lines, respectively, and compared with the experimental valence band recorded with photon energy of $250 \mathrm{eV}$.

the partial density of states (PDOS) of the different elements of $\mathrm{CH}_{3} \mathrm{NH}_{3} \mathrm{PbI}_{3}$ (in red) and $\mathrm{CH}_{3} \mathrm{NH}_{3} \mathrm{PbBr}_{3}$ (in green) from the DFT calculations. The separate s- and p- orbital contributions are presented together with the experimental spectrum at 250 $\mathrm{eV}$ exhibiting more resolved structures. The general shape of the calculated spectra is in line with previous reports. ${ }^{31,47}$

As a brief summary of the calculations, we note that the band edge for $\mathrm{CH}_{3} \mathrm{NH}_{3} \mathrm{PbI}_{3}$ is dominated by a large feature at 2-6 $\mathrm{eV}$ ascribed mainly to I 5p. Moreover, the halide orbitals are mixing with the lead orbitals in the inorganic framework of the hybrid perovskite states forming a valence band edge, which in the literature has been conceptually divided into an upper and a lower part. ${ }^{48}$ At the very top of the valence band (peak I) around $2 \mathrm{eV}$ in $\mathrm{CH}_{3} \mathrm{NH}_{3} \mathrm{PbI}_{3}$, there is a mixing between I $5 \mathrm{p}$ and $\mathrm{Pb} 6 \mathrm{~s}$, whereas further down at the high-energy side $(6 \mathrm{eV}$, peak II) of that feature, the lead contribution is predominantly of $\mathrm{Pb} 6 \mathrm{p}$ character. The overlap between the I $5 \mathrm{p}$ and $\mathrm{Pb} 6 \mathrm{~s}$ and $\mathrm{Pb} 6 \mathrm{p}$ orbitals results in bonding and antibonding combinations, which in the crystal is broadened by dispersions in the bands and the formation of the lowest states in the conduction band, as depicted in Figure 4. The orbital mixing in the calculations is also seen in the I $5 s-\mathrm{Pb} 6 \mathrm{p}$ feature at $14 \mathrm{eV}$ (peak VI), whereas the feature at $10 \mathrm{eV}$ (peak IV) is nearly pure $\mathrm{Pb}$ 6s. In $\mathrm{CH}_{3} \mathrm{NH}_{3} \mathrm{PbBr}_{3}$, the corresponding features are downshifted by increasing amounts from $+2 \mathrm{eV}$ for $\mathrm{Br} 4 \mathrm{p}$ and to $+4 \mathrm{eV}$ for $\mathrm{Br} 4 \mathrm{~s}$. We want especially to bring the reader's attention to the strong sensitivity in the $\mathrm{Pb} 6 \mathrm{p}$ character at 2-6 $\mathrm{eV}$ and $10-14 \mathrm{eV}$ to the PDOS of the halide ion. This is a direct consequence of the difference in binding energies for $\mathrm{Br}^{-}$ and $\mathrm{I}^{-}$, as noted previously (ref 31 ). The binding energies of the levels of the counterion are likewise affected by a uniform shift upon replacement of the halide ions. Notice that at low binding energies around $7 \mathrm{eV}$ (peak III), the $\mathrm{C} 2 \mathrm{p}$ orbitals dominate, and further down at $12 \mathrm{eV}$ (peak V), the $\mathrm{N} 2 \mathrm{p}$ orbitals dominate, because nitrogen has a higher nuclear charge but also a deficiency of electron density because the cationic charge is centered around the ammonium group. Based on these considerations, the TDOS and PDOS are compared to the energy diagrams of $\left[\mathrm{PbBr}_{6}\right]^{-}$and $\left[\mathrm{PbI}_{6}\right]^{-}$clusters in Figure 4.

While the theoretical discussion above was based on the simpler model systems for clarity, we also controlled the general outcome by performing a calculation on a mixed perovskite (Figure S3), and this calculation clearly supports the present discussion in terms of character for the different features observed in the valence level measurements. Before calculating the PDOS, we performed a rigorous structural search and refined them through structural optimization to find the minimum energy configuration for the structure for the mixed perovskite: $\mathrm{FA}_{0.83} \mathrm{MA}_{0.17} \mathrm{~Pb}\left(\mathrm{I}_{0.83} \mathrm{Br}_{0.17}\right)_{3}$. As depicted in Figure $\mathrm{S} 3$, we generally observe contributions similar to the ones discussed for the model systems above. Specifically, the iodine and bromine $\mathrm{p}$ and $\mathrm{s}$ contributions are very similar. The contribution of the $\mathrm{Pb} \mathrm{s}$ is more pronounced around $7 \mathrm{eV}$, while the contribution at $10 \mathrm{eV}$ is much lower, possibly connected to limitations or differences in the pseudopotentials. The contributions of nitrogen and carbon look similar, despite the mixed cations in the realistic model, but with some increased mixing with the inorganic framework.

3.2.2. Effect of the Photon Energy on the Valence Structure. The total DOS of $\mathrm{CH}_{3} \mathrm{NH}_{3} \mathrm{PbI}_{3}(\mathrm{~s})$ and $\mathrm{CH}_{3} \mathrm{NH}_{3} \mathrm{PbBr}_{3}(\mathrm{~s})$ in Figures 3 and 4 do not take into account the cross section of the different orbitals. For comparison to the experiments, the PDOS of specific orbital character of specific elements were multiplied with the photoionization cross sections in Figure $2 \mathrm{~b}$ to enable direct simulation of the measured evolution of the valence band spectra of mixed perovskite materials as a function of the photon energy. The resulting simulated TDOS are presented and compared with the experimental spectra in Figure 5. The structures assigned to the organic part (i.e., $\mathrm{C} 2 \mathrm{p}$ and $\mathrm{N} 2 \mathrm{p}$, peak III and V, respectively) are labeled in blue, whereas the inorganic structures are marked in red. The simulated PES data show that apart from the absence of $\mathrm{Pb} 5 \mathrm{~d}$ level (which were only 


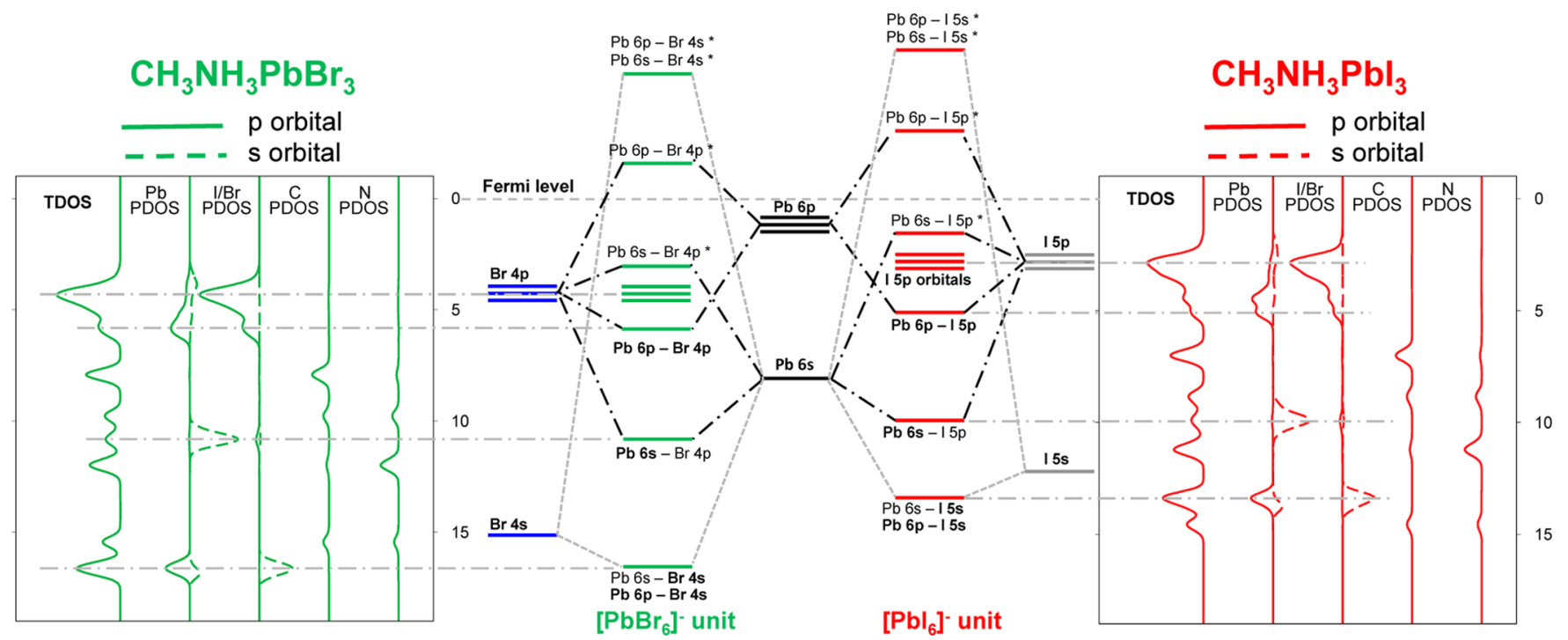

Figure 4. TDOS and PDOS of the $\mathrm{CH}_{3} \mathrm{NH}_{3} \mathrm{PbI}_{3}$ and $\mathrm{CH}_{3} \mathrm{NH}_{3} \mathrm{PbBr}_{3}$ models related to the energy diagram of the $\left[\mathrm{PbBr}_{6}\right]^{-}$and $\left[\mathrm{PbI}_{6}\right]^{-}$units (inspired by and adapted from refs 48 and 49 ).
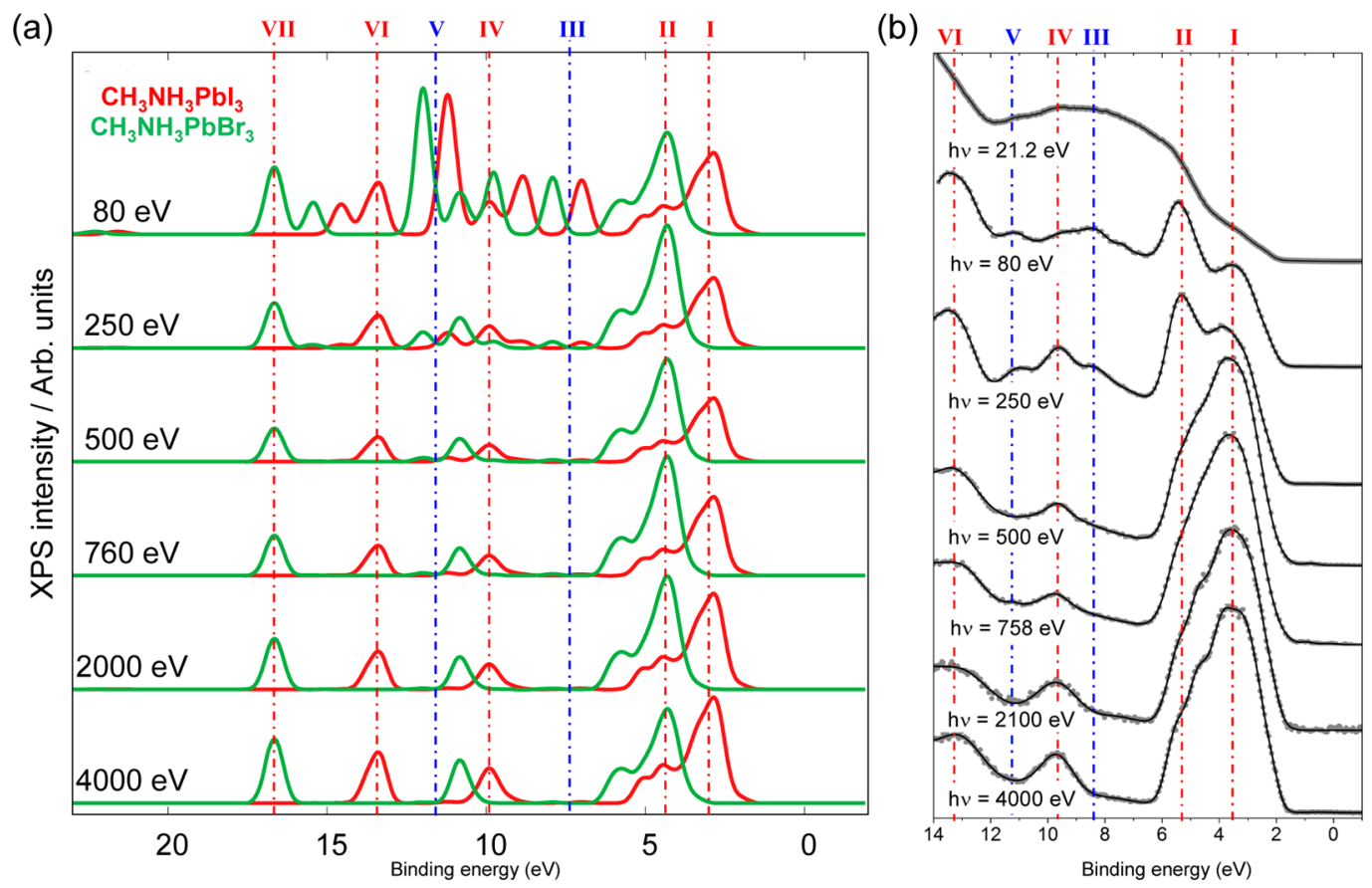

Figure 5. (a) Simulated photoelectron spectra of the $\mathrm{CH}_{3} \mathrm{NH}_{3} \mathrm{PbI}_{3}$ and $\mathrm{CH}_{3} \mathrm{NH}_{3} \mathrm{PbBr}_{3}$ models. The photon energy dependence is constructed by combining the photoionization cross section in Figure 2 with the partial density of states (PDOS) of each element and its orbital characters. (b) Evolution of the valence band spectra (14-0 eV binding energy range) of the mixed perovskite materials as a function of the photon energy.

implicitly included in the pseudopotentials), the general trend of the experimental data can be reproduced. At high energies $(>500 \mathrm{eV})$, the ionization of heavy elements (lead and halides) dominates the PES data at $4 \mathrm{eV}$ and $10-18 \mathrm{eV}$. Even though the levels at these energies involve electronic bands formed with orbital contributions from several elements, the energy dependence of their cross sections exhibits the same behavior as those of the contributing atomic levels. At low energies $(<500$ $\mathrm{eV}$ ), we notice the appearance of features in the intermediate region related to the lighter elements, carbon $2 \mathrm{p}$ and nitrogen 2p. Note that the simulated PES spectra underestimate the intensity in the feature IV, related to lead, observed in the experimental data, and relative weights of different orbital contributions could be further adjusted to fit the experiments. We can also notice that the change in the relative weight of feature VI (I 5s contribution) is underestimated in the simulations.

As previously predicted from the evolution of the cross sections, more spectral structures can be resolved with a low photon energy. Such considerations clearly highlight the difference expected when comparing traditional UPS with synchrotron-based SOXPES and HAXPES data. At low photon energy $(21.2 \mathrm{eV})$, levels with $\mathrm{p}$ character of both light ( $\mathrm{C}$ and $\mathrm{N})$ and heavy $(\mathrm{Pb}, \mathrm{I}, \mathrm{Br})$ elements have a high cross section, while heavy elements and specifically $\mathrm{Br} 4 \mathrm{p}$ and I $5 \mathrm{p}$ mainly will dominate the spectra obtained when using high photon 
energies. Moreover, with an energy of $21.2 \mathrm{eV}$, we note that features from the I $5 p$ and $\mathrm{Br} 4 \mathrm{p}$ (peaks I and II) are less strong although their relative cross sections versus the $\mathrm{MA}^{+}$and $\mathrm{FA}^{+}$ constituents are a few orders of magnitude higher. At this point we also have to remember that the surface may contain some inhomogeneity and/or contamination and that the IMFP for the lower photon energy regime is still relatively short compared to the one reached by energies used in HAXPES measurements. As a consequence, the signal originating from the outermost surface including carbon-based surface contamination will be significantly enhanced in UPS, complicating the interpretation of low photon energy PES of such material.

Now that we have a better understanding of the valence band structures, a deeper discussion can occur on the basis of these spectra. As an example, the valence spectra of the mixed perovskite either stoichiometrically prepared or with a deliberate deficiency of $\mathrm{PbI}_{2}(-10 \%)$ have also been recorded with the same energies, and the full set of spectra is presented in the Supporting Inormation (Figure S4). The spectra recorded at 80 and $4000 \mathrm{eV}$ of the $-10 \%, 0 \%$, and $+10 \%$ are shown in Figure 6. The spectra at $4000 \mathrm{eV}$ are all very similar,
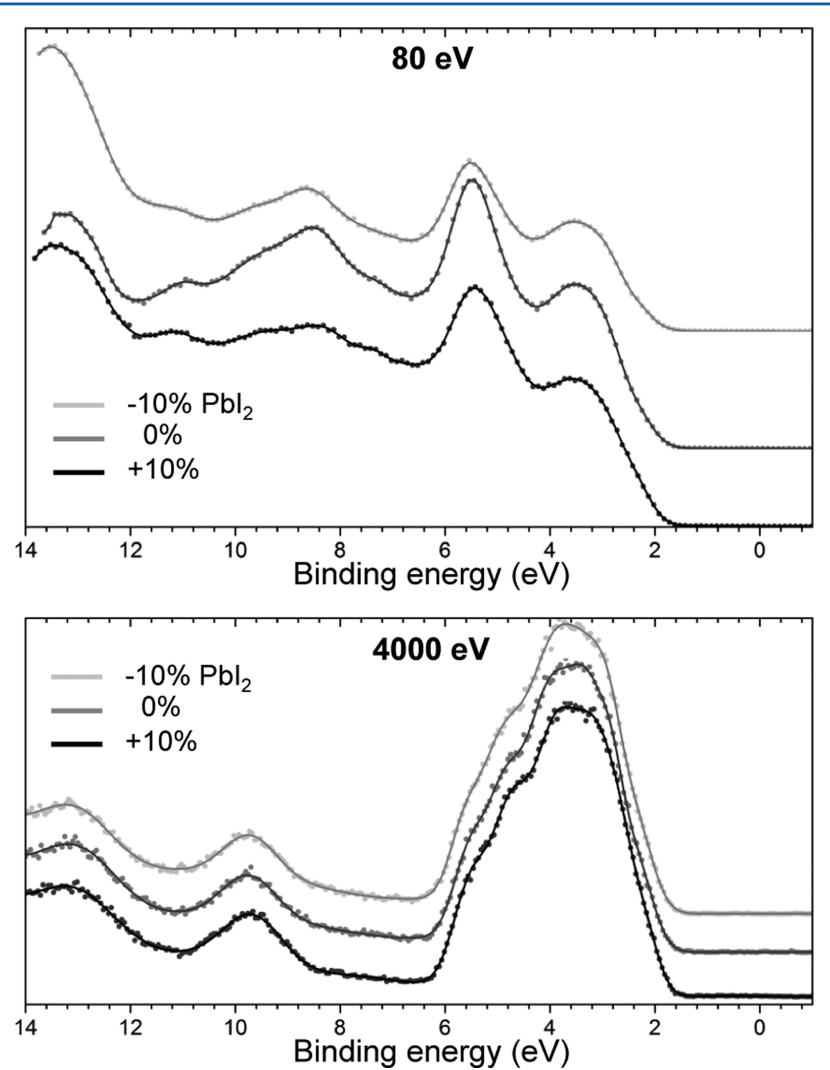

Figure 6. Comparison of the valence band spectra of three mixed perovskite samples recorded at 80 and $4000 \mathrm{eV}$. The sample labeled as $0 \%$ was prepared using a stoichiometric precursor, while the two other samples were prepared via a nonstoichiometric precursor solution with either an excess of $\mathrm{Pb}_{2}(+10 \%)$ or a deficiency of $\mathrm{PbI}_{2}(-10 \%)$.

while variations can be observed at $80 \mathrm{eV}$. Our previous investigation through the core levels has revealed that these three materials contain $\mathrm{PbI}_{2}$ below the surface with greater amount when going from the $-10 \%$ to the $+10 \%$ samples. At the surface, a slight excess of the organic part of the perovskite in the form of formamidinium iodide (FAI) was detected with larger amounts present for the $-10 \%$ sample. ${ }^{18}$ The valence at
$4000 \mathrm{eV}$ is dominated by the inorganic part of the perovskite, i.e., the $\mathrm{PbI}_{6}$ octahedra having a similar electronic structure as $\mathrm{PbI}_{2}$; therefore, not so much difference can be seen in the spectra. In the spectra at $80 \mathrm{eV}$, the sensitivity is higher for the light elements, and the differences observed can be due to the different amounts of organic part present at the surface as well as different levels of contamination. In addition, the $-10 \%$ sample has a more intense peak around $14 \mathrm{eV}$ (assigned to I 5s) compared to the other sample, in good agreement with the iodide excess detected at the surface.

We have described the origin of the variations in the valence band structure in the first part of this paper. In short, when translating PES spectra into DOS plots, it is important to take the ionization cross sections into account in the interpretation. At selected photon energies, the PES spectra are more closely related to partial density of state (PDOS) plots reflecting a set of orbital characters. We have also discussed how the chemistry, i.e., different surface compositions, can influence the overall shape of a valence band spectrum.

3.3. Estimation of the Valence Band Maxima. The determination and control of the valence band edge (or valence band maximum, VBM) is an important parameter for the development of full solar cell devices. The determination of the precise VBM allows the drawing of the band energy alignment diagram.

An approach to estimate the VBM but also the position of the conduction band minimum (CBM) is generally achieved by combining PES and inverse PES (IPES). ${ }^{50-52} \mathrm{~A}$ different approach for estimating a complete band energy diagram, as presented in Figure 7, is to determine the position of the VBM in relation to the Fermi level $\left(E_{\mathrm{f}}\right)$ using PES and to determine CBM from the optical band gap $\left(E_{\mathrm{g}}\right)$. The optical band gap is generally determined using ultraviolet-visible diffuse reflectance spectroscopy via a Tauc plot ${ }^{53,54}$ or more directly by photoluminescence spectroscopy. ${ }^{55}$ The position of the CBM can thus be deduced as shown in Figure 7a. The measurement of the work function $\Phi$ of the surface of the material of interest is necessary if we want to present an energy band diagram versus the vacuum level, as shown in Figure $7 \mathrm{~b}$. The work function $\Phi$ of the material is generally measured using either PES or Kelvin probe measurements. ${ }^{56}$

The following discussion will mainly focus on the determination of the VBM versus $E_{\mathrm{f}}$. The energy difference between $E_{\mathrm{f}}$ and VBM is often determined by PES using either UPS or XPS. The first step consists in the calibration of the spectra, which is generally done by measuring a well-defined reference, e.g., clean silver or gold, and setting its Fermi edge at $0 \mathrm{eV}$ binding energy. Second, one needs a procedure to determine the VBM from an experimental spectrum with a shape of the outermost structure that, among other things, for a pristine sample depends on the density of state, cross sections, and crystal orientations together with experimental effects such as resolution and signal-to-noise levels. The estimation of the VBM is often determined through an extrapolation procedure.

The most common approach is to use a linear extrapolation of the outermost edge of the valence band, ${ }^{50,53,57}$ although this can clearly be questionable for many samples. Trends in a VBM value with an accuracy of about $\pm 0.1 \mathrm{eV}$ have been estimated for different families of samples. ${ }^{58}$ The use of this approach for the different valence band spectra of our mixed perovskite recorded at various photon energies is presented in Figure 8a,b for the $+10 \%$ material (extrapolation of the $-10 \%$ and $0 \%$ materials are found in Figures S5 and S6, respectively). The 
(a)

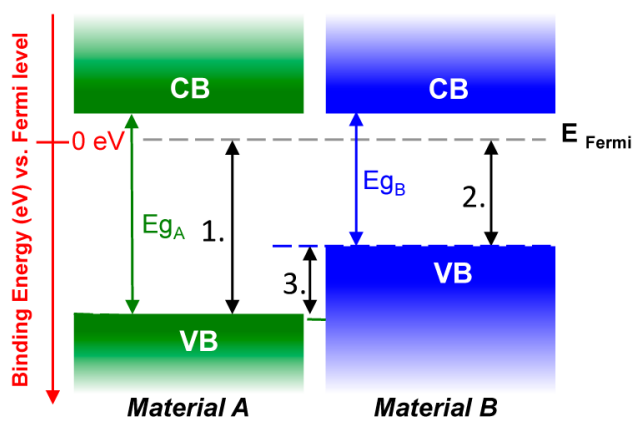

(b)

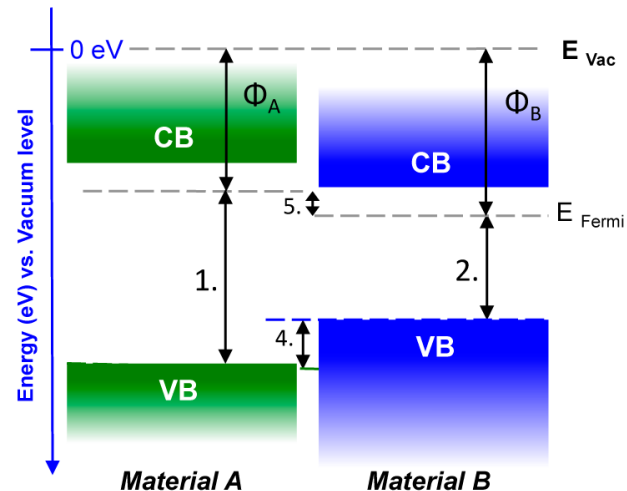

Figure 7. Schematic of a band energy alignment diagram of two materials (A and B) presented as a function of (a) the Fermi level or (b) the vacuum level. In this schematic, the difference between the VBM of two materials is noted as 3 in panel a and as 4 in panel $b$. This difference is linked by the relation $3=4+5$, where 5 is the difference in the work function of materials $\mathrm{A}$ and $\mathrm{B}$.

Non-stoichiometric mixed perovskite $\left(+10 \% \mathrm{Pbl}_{2}\right)$
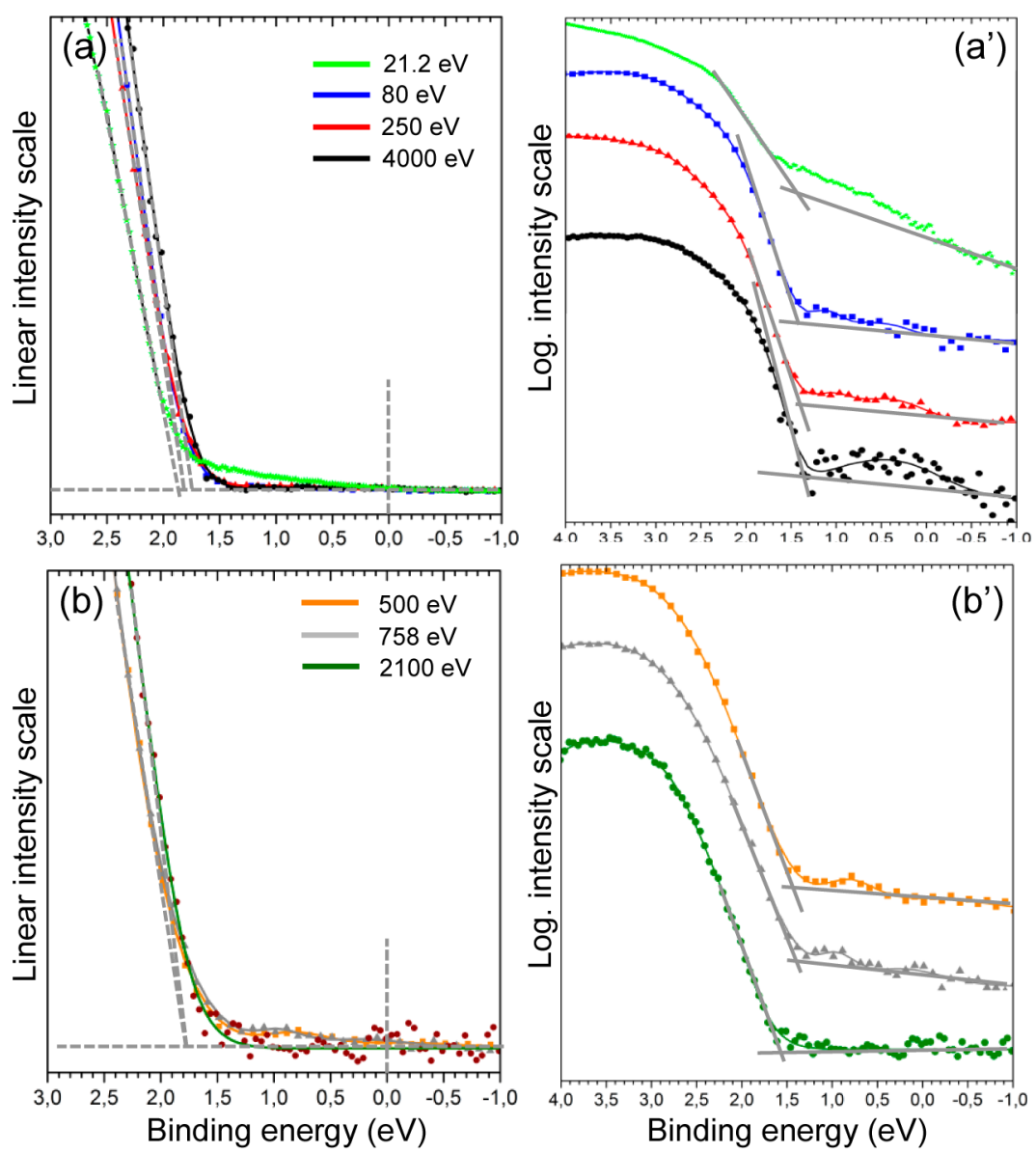

Figure 8. Valence level spectra of the mixed perovskite material measured at different energies: 21.2, 80, 250, 500, 758, 2100, and 4000 eV. The valence band maximum (VBM) was estimated in two different ways using a "linear extrapolation" ( $a, b)$ and a "logarithmic extrapolation" ( $a$ ', $b^{\prime}$ ). For both methods, the VBM was taken as the energy value at the intercept of two lines extrapolating the baseline and the main intensity drop. These intersections are presented as gray lines. A linear intensity scale was used for the "linear extrapolation", while a logarithmic intensity scale was used for the "logarithmic extrapolation". The estimated VBE values determined by using these two approaches are plotted in Figure 9.

extracted VBM values are presented in Figure 9 as a function of photon energy for the three different materials $(+10 \%, 0 \%$, and $-10 \% \mathrm{PbI}_{2}$ ). This linear extrapolation is relatively easy to apply as long as the signal/noise ratio is reasonable and the distribution of the results obtained for the different excitation energies is relatively narrow. However, for the perovskite family of samples investigated here, such an approach often leads to absolute values that have to be treated with care. In the present case, all VBM values estimated using a linear approach are around 1.7-1.8 eV, which is higher than the band gap 


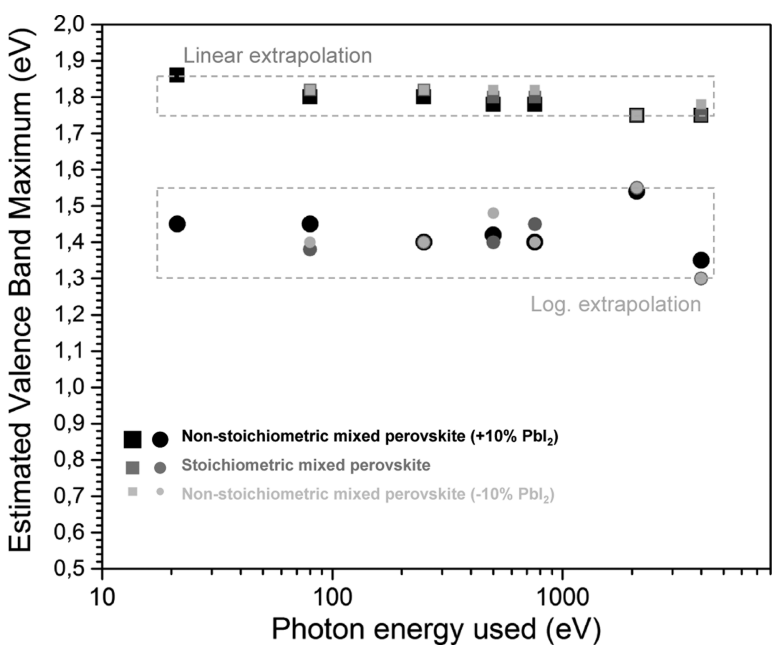

Figure 9. Estimated VBM of three mixed perovskites $(-10 \%, 0 \%$, $+10 \%$ in light gray, gray, and black, respectively) determined using the linear (squares) and the logarithmic extrapolation (circles) plotted as a function of the photon energy $(h \nu)$ used. The UPS measurement $(h \nu$ $=21.2 \mathrm{eV})$ was measured for only one sample $(+10 \%)$.

estimated to be $1.6 \mathrm{eV}$ for this material, and thus would indicate a Fermi level located within the conduction band. A similar finding was also observed for $\mathrm{TiO}_{2}$ using either UPS or HAXPES. ${ }^{53,59}$

An alternative procedure to estimate the absolute position of the VBM was more recently used. ${ }^{60}$ States at low binding energies were emphasized by plotting the spectra on a logarithmic intensity scale, and the shape of the valence band edge was compared to theoretical calculations. In such a procedure, largely treating the DOS increase as exponential, the VBM is determined when the intensity drops toward zero and generally occurs closer to the Fermi level than in the previous approach. This approach is shown in Figure $8 a^{\prime}, b^{\prime}$ for the $+10 \%$ sample (see Figures S5 and S6 for the $-10 \%$ and $0 \%$ samples, respectively), and the corresponding extrapolated VBM are also summarized in Figure 9. The VBMs using a logarithmic scale are found to be approximately $0.4 \mathrm{eV}$ lower than the VBM estimated with a traditional approach. Energy diagrams resulting from such a process combined with values obtained from optical band gaps become more realistic, as the position of the Fermi level lies within the band gap. However, this latter extrapolation is not always trivial and well-defined because noise may dominate the band gap region.

The valence band spectra around $0 \mathrm{eV}$ binding energy can be seen in the Figure S7. While the signal is mainly dropping in intensity at energies between 2 and $1 \mathrm{eV}$, we can note that there is still signal detected between $1 \mathrm{eV}$ and the Fermi level at $0 \mathrm{eV}$. This remaining signal in what may be considered as the band gap region could largely be due to the presence of metallic lead with a density of state down to the Fermi level. ${ }^{46,59}$ Signal originating from higher orders of light of the synchrotron radiation can also contribute to the detected counts.

The VBMs obtained with both approaches are presented in Figure 9 and show that the "linear extrapolation" gives results with a better accuracy $( \pm 0.1 \mathrm{eV})$ while the "logarithmic extrapolation" gives more realistic values with less precision $( \pm 0.2 \mathrm{eV})$. In addition, we can also see that for the mixed perovskite materials measured here an estimation of the VBM is not necessarily energy-dependent, and results obtained by UPS, XPS, or HAXPES are all very similar. This result is certainly not expected for all materials and is a consequence of the character of the valence band edge being clearly dominated by I 5 p.

\section{CONCLUSIONS}

The valence band spectra of a mixed perovskite were investigated by photoelectron spectroscopy using different photon energies (UPS, SOXPES, and HAXPES) combined with DFT calculations. A detailed insight of the valence structure beyond the valence band edge was obtained showing how the intensity of different contributions can be enhanced by changing the photon energy of the incident source. Photon energies higher than $500 \mathrm{eV}$ give a valence band where contributions of the heavy inorganic elements, i.e., iodine, lead, and bromine, are dominant while the organic cations states will be more visible when lower photon energies are used. The variation of the IMFP is also directly linked to the change in photon energy, and the carbon-containing contamination present at the surface will also be enhanced when low photon energies are used.

Important in solar cell engineering, we showed that the VBM energy values, which generally are extracted from the valence band spectra, show only minor variations with the photon energy used. Hence, UPS and HAXPES can give similar results for these kind of materials, indicating that relative changes in VBM can be followed with high accuracy using either technique. The main contribution to the valence structure around the VBM comes from I 5p/Br $4 p$, and a modification of the photon energy will impact only its intensity and not its position. We compared two approaches to determine the VBM using either a linear or a logarithmic intensity scale. A difference of about $0.4 \mathrm{eV}$ is found between these two approaches in the case of a set of three different mixed perovskite materials. If the energy difference between the VBM and the Fermi level of a material is to be determined, a conversion of the intensity scale to a logarithmic intensity, thus capturing lower densities of states, will give more realistic results.

\section{ASSOCIATED CONTENT}

\section{Supporting Information}

The Supporting Information is available free of charge on the ACS Publications website at DOI: 10.1021/acs.jpcc.7b08948.

C 1s core level spectra of the mixed perovskite $(+10 \%$ $\mathrm{PbI}_{2}$ ) as a function of the photon energy; evolution of the photoionization cross section of $\mathrm{I} 3 \mathrm{~d}, \mathrm{~Pb} 4 \mathrm{f}, \mathrm{Br} 3 \mathrm{~d}, \mathrm{O}$ $1 \mathrm{~s}, \mathrm{~N} \mathrm{1s}$, and $\mathrm{C} 1 \mathrm{~s}$ as a function of the photon energies; DFT calculation on the stoiechiometric mixed perovskite, calculation details, and results; evolution of the experimental valence band spectra of the stoichiometric and $-10 \% \mathrm{PbI}_{2}$ mixed perovskite materials as a function of the photon energy; linear and logarithmic extrapolation of the VBM on the stoichiometric and $-10 \%$ $\mathrm{PbI}_{2}$ mixed perovskite materials (PDF)

\section{AUTHOR INFORMATION}

\section{Corresponding Authors}

*E-mail: bertrand.philippe@physics.uu.se.

*E-mail: hakan.rensmo@physics.uu.se.

ORCID ${ }^{\circ}$

Bertrand Philippe: 0000-0003-2412-8503

T. Jesper Jacobsson: 0000-0002-4317-2879

Juan-Pablo Correa-Baena: 0000-0002-3860-1149 
Naresh K. Jena: 0000-0002-8242-8005

Amitava Banerjee: 0000-0002-3548-133X

Sudip Chakraborty: 0000-0002-6765-2084

Ute B. Cappel: 0000-0002-9432-3112

Rajeev Ahuja: 0000-0003-1231-9994

Michael Odelius: 0000-0002-7023-2486

\section{Notes}

The authors declare no competing financial interest.

\section{ACKNOWLEDGMENTS}

We acknowledge financial support from the Swedish Research Council, the Swedish Energy Agency, the Swedish Foundation for Strategic Research, the ÅForsk foundation , and StandUP for Energy. HZB is acknowledged for the allocation of synchrotron radiation beamtime as well as MAX IV laboratory. The computations were performed on resources provided by the Swedish National Infrastructure for Computing (SNIC) at the Swedish National Supercomputer Center (NSC), the High Performance Computer Center North (HPC2N), and Chalmers Centre for Computational Science and Engineering (C3SE).

\section{REFERENCES}

(1) Green, M. A. Commercial Progress and Challenges for Photovoltaics. Nat. Energy 2016, 1, 15015.

(2) Green, M. A.; Bremner, S. P. Energy Conversion Approaches and Materials for High-Efficiency Photovoltaics. Nat. Mater. 2017, 16, 2334.

(3) Kojima, A.; Teshima, K.; Shirai, Y.; Miyasaka, T. Organometal Halide Perovskites as Visible-Light Sensitizers for Photovoltaic Cells. J. Am. Chem. Soc. 2009, 131, 6050-6051.

(4) Liu, C.; Ding, W.; Zhou, X.; Gao, J.; Cheng, C.; Zhao, X.; Xu, B. Efficient and Stable Perovskite Solar Cells Prepared in Ambient Air Based on Surface-Modified Perovskite Layer. J. Phys. Chem. C 2017, 121, 6546-6553.

(5) Chen, J.; Song, J.; Huang, F.; Li, H.; Liu, S.; Wang, M.; Shen, Y. The Role of Synthesis Parameters on Crystallization and Grain Size in Hybrid Halide Perovskite Solar Cells. J. Phys. Chem. C 2017, 121, 17053-17061.

(6) Xiang, Y.; Ma, Z.; Zhuang, J.; Lu, H.; Jia, C.; Luo, J.; Li, H.; Cheng, X. Enhanced Performance for Planar Perovskite Solar Cells with Samarium-Doped $\mathrm{TiO}_{2}$ Compact Electron Transport Layers. J. Phys. Chem. C 2017, 121, 20150-20157.

(7) Lin, K.-H.; Prlj, A.; Corminboeuf, C. A Rising Star: Truxene as a Promising Hole Transport Material in Perovskite Solar Cells. J. Phys. Chem. C 2017, 121, 21729-21739.

(8) Kim, H.-S.; Seo, J.-Y.; Park, N.-G. Impact of Selective Contacts on Long-Term Stability of $\mathrm{CH}_{3} \mathrm{NH}_{3} \mathrm{PbI}_{3}$ Perovskite Solar Cells. J. Phys. Chem. C 2016, 120, 27840-27848.

(9) Han, G. S.; Song, Y. H.; Jin, Y. U.; Lee, Y.-W.; Park, N.-G.; Kang, B. K.; Lee, J.-K.; Cho, Y. S.; Yoon, D. H.; Jung, H. S. Reduced Graphene Oxide/Mesoporous $\mathrm{TiO}_{2}$ Nanocomposite Based Perovskite Solar Cells. ACS Appl. Mater. Interfaces 2015, 7, 23521-23526.

(10) NREL Chart. www.nrel.gov/pv/assets/images/efficiency-chart. png (accessed August 15, 2017).

(11) Yang, W. S.; Park, B.-W.; Jung, E. H.; Jeon, N. J.; Kim, Y. C.; Lee, D. U.; Shin, S. S.; Seo, J.; Kim, E. K.; et al. Iodide Management in Formamidinium-Lead-Halide-Based Perovskite Layers for Efficient Solar Cells. Science 2017, 356, 1376-1379.

(12) Correa-Baena, J. - P.; Abate, A.; Saliba, M.; Tress, W.; Jacobsson, T. J.; Grätzel, M.; Hagfeldt, A. The Rapid Evolution of Highly Efficient Perovskite Solar Cells. Energy Environ. Sci. 2017, 10, 710-727.

(13) Park, N. - G.; Grätzel, M.; Miyasaka, T.; Zhu, K.; Emery, K. Towards Stable and Commercially Available Perovskite Solar Cells. Nat. Energy 2016, 1, 16152.
(14) Eperon, G. E.; Leijtens, T.; Bush, K. A.; Prasanna, R.; Green, T.; Wang, J. T. W.; McMeekin, D. P.; Volonakis, G.; Milot, R. L.; May, R.; et al. Perovskite - Perovskite Tandem Photovoltaics with Optimized Bandgaps. Science 2016, 354, 861.

(15) Wei, L.-Y.; Ma, W.; Lian, C.; Meng, S. Benign Interfacial Iodine Vacancies in Perovskite Solar Cells. J. Phys. Chem. C 2017, 121, 59055913.

(16) Park, B.-W.; Philippe, B.; Jain, S. M.; Zhang, X.; Edvinsson, T.; Rensmo, H.; Zietz, B.; Boschloo, G. Chemical Engineering of Methylammonium Lead Iodide/Bromide Perovskites: Tuning of Optoelectronic Properties and Photovoltaic Performance. J. Mater. Chem. A 2015, 3, 21760-21771.

(17) Zuo, L.; Chen, Q.; De Marco, N.; Hsieh, Y.-T.; Chen, H.; Sun, P.; Chang, S. Y.; Zhao, H.; Dong, S.; Yang, Y. Tailoring the Interfacial Chemical Interaction for High-Efficiency Perovskite Solar Cells. Nano Lett. 2017, 17, 269-275.

(18) Jacobsson, T. J.; Correa-Baena, J.-P.; Anaraki, E. H.; Philippe, B.; Stranks, S. D.; Bouduban, M. E. F.; Tress, W.; Schenk, K.; Teuscher, J.; Moser, J.-E.; et al. Unreacted $\mathrm{PbI}_{2}$ as a Double-Edged Sword for Enhancing the Performance of Perovskite Solar Cells. J. Am. Chem. Soc. 2016, 138, 10331-10343.

(19) Bi, D.; Tress, W.; Dar, m. I.; Gao, P.; Luo, J.; Renevier, C.; Schenk, K.; Abate, A.; Giordano, F.; Correa Baena, J. -P; et al. Efficient Luminescent Solar Cells Based on Tailored Mixed-Cation Perovskites. Sci. Adv. 2016, 2, e1501170.

(20) Jacobsson, T. J.; Correa-Baena, J.-P.; Pazoki, M.; Saliba, M.; Schenk, K.; Gratzel, M.; Hagfeldt, A. Exploration of the Compositional Space for Mixed Lead Halogen Perovskites for High Efficiency Solar cells. Energy Environ. Sci. 2016, 9, 1706-1724.

(21) Saliba, M.; Matsui, T.; Seo, J.-Y.; Domanski, K.; Correa-Baena, J.- P.; Nazeeruddin, M. K.; Zakeeruddin, S. M.; Tress, W.; Abate, A.; Hagfeldt, A.; et al. Cesium-Containing Triple Cation Perovskite Solar Cells: Improved Stability, Reproducibility and High Efficiency. Energy Environ. Sci. 2016, 9, 1989-1997.

(22) Saliba, M.; Matsui, T.; Domanski, K.; Seo, J.-Y.; Ummadisingu, A.; Zakeeruddin, S. M.; Correa Baena, J.-P.; Tress, W. R.; Abate, A.; Hagfeldt, A.; Grätzel, M. Incorporation of Rubidium Cations into Perovskite Solar Cells improves Photovoltaic Performance. Science 2016, 354, 206-209.

(23) Albadri, A.; Yadav, P.; Alotaibi, M.; Arora, N.; Alyamani, A.; Albrithen, H.; Dar, M. I.; Zakeeruddin, S. M.; Grätzel, M. Unraveling the Impact of Rubidium Incorporation on the Transport-Recombination Mechanisms in Highly Efficient Perovskite Solar Cells by SmallPerturbation Techniques. J. Phys. Chem. C 2017, 121, 24903.

(24) Schäfers, F.; Mertin, M.; Gorgoi, M. KMC-1: a High Resolution and High Flux Soft X-ray Beamline at BESSY. Rev. Sci. Instrum. 2007, 78,123102 .

(25) Gorgoi, M.; Svensson, S.; Schäfers, F.; Öhrwall, G.; Mertin, M.; Bressler, P.; Karis, O.; Siegbahn, H.; Sandell, A.; Rensmo, H.; et al. The High Kinetic Energy Photoelectron Spectroscopy Facility at BESSY Progress and First Results. Nucl. Instrum. Methods Phys. Res., Sect. A 2009, 601, 48-53.

(26) Tanuma, S.; Powell, C. J.; Penn, D. R. Calculations of Electron Inelastic Mean Free Paths. Surf. Interface Anal. 1994, 21, 165-176.

(27) Yeh, J. J.; Lindau, I. Atomic Subshell Photoionoization Cross Sections and Asymmetry Parameters: $1 \leq \mathrm{Z} \leq 103$. At. Data Nucl. Data Tables 1985, 32, 1-155.

(28) Yeh, J. J. Atomic Calculations of Photoionization Cross Sections and Asymmetry Parameters. Gordon and Breach: Langhorne, PA, 1993.

(29) Atomic Calculations of Photoionization Cross Sections and Asymmetry Parameters. Elettra; https://vuo.elettra.trieste.it/services/ elements/WebElements.html.

(30) Scofield, J. H. Lawrence Livermore Laboratory, Theoretical Photoionization Cross Sections from 1 to $1500 \mathrm{keV}$; University of California: Livermore, CA, 1973.

(31) Lindblad, R.; Jena, N. K.; Philippe, B.; Oscarsson, J.; Bi, D.; Lindblad, A.; Mandal, S.; Pal, B.; Sarma, D. D.; Karis, O.; Siegbahn, H.; et al. The Electronic Structure of $\mathrm{CH}_{3} \mathrm{NH}_{3} \mathrm{PbX}_{3}$ Perovskites; the 
Dependence on the Halide Moiety. J. Phys. Chem. C 2015, 119, 18181825.

(32) CP2K Developers Group. CP2K, version 2.7; 2015; http:// www.cp2k.org.

(33) Hutter, J.; Iannuzzi, M.; Schiffmann, F.; VandeVondele, J. CP2K: Atomistic Simulations of Condensed Matter Systems. Wiley Interdiscip. Rev. Comput. Mol. Sci. 2014, 4, 15-25.

(34) VandeVondele, J.; Krack, M.; Mohamed, F.; Parrinello, M.; Chassaing, T.; Hutter, J. Quickstep: Fast and Accurate Density Functional Calculations Using a Mixed Gaussian and Plane Waves Approach. Comput. Phys. Commun. 2005, 167, 103-128.

(35) Lippert, G.; Hutter, J.; Parrinello, M. A Hybrid Gaussian and Plane Wave Density Functional Scheme. Mol. Phys. 1997, 92, 477488.

(36) Becke, A. D. Density-Functional Exchange-Energy Approximation with Correct Asymptotic Behavior. Phys. Rev. A: At., Mol., Opt. Phys. 1988, 38, 3098-3100.

(37) Lee, C.; Yang, W.; Parr, R. G. Development of the Colle-Salvetti Correlation-Energy Formula into a Functional of the Electron Density. Phys. Rev. B: Condens. Matter Mater. Phys. 1988, 37, 785-789.

(38) Grimme, S.; Ehrlich, S.; Goerigk, L. Effect of the Damping Function in Dispersion Corrected Density Functional Theory. J. Comput. Chem. 2011, 32, 1456-1465.

(39) Grimme, S.; Antony, J.; Ehrlich, S.; Krieg, H. A Consistent and Accurate $\mathrm{Ab}$ Initio Parametrization of Density Functional Dispersion Correction (DFT-D) for the 94 Elements H-Pu. J. Chem. Phys. 2010, 132, 154104.

(40) Krack, M. Pseudopotentials for $\mathrm{H}$ to Kr Optimized for GradientCorrected Exchange-Correlation Functionals. Theor. Chem. Acc. 2005, $114,145-152$.

(41) Hartwigsen, C.; Goedecker, S.; Hutter, J. Relativistic Separable Dual-Space Gaussian Pseudopotentials from H to Rn. Phys. Rev. B: Condens. Matter Mater. Phys. 1998, 58, 3641-3662.

(42) Goedecker, S.; Teter, M.; Hutter, J. Separable Dual-Space Gaussian Pseudopotentials. Phys. Rev. B: Condens. Matter Mater. Phys. 1996, 54, 1703-1710.

(43) VandeVondele, J.; Hutter, J. Gaussian Basis Sets for Accurate Calculations on Molecular Systems in Gas and Condensed Phases. J. Chem. Phys. 2007, 127, 114105.

(44) Philippe, B.; Saliba, M.; Correa-Baena, J.-P.; Cappel, U. B.; Turren-Cruz, S.-H.; Grätzel, M.; Hagfeldt, A.; Rensmo, H. Chemical Distribution of Multiple Cation $\left(\mathrm{Rb}^{+}, \mathrm{Cs}^{+}, \mathrm{MA}^{+}\right.$, and $\left.\mathrm{FA}^{+}\right)$Perovskite Materials by Photoelectron Spectroscopy. Chem. Mater. 2017, 29, 3589-3596.

(45) Qin, C.; Matsushima, T.; Fujihara, T.; Adachi, C. Multifunctional Benzoquinone Additive for Efficient and Stable Planar Perovskite Solar Cells. Adv. Mater. 2017, 29, 1603808.

(46) Sadoughi, G.; Starr, D. E.; Handick, E.; Stranks, S. D.; Gorgoi, M.; Wilks, R. G.; Bär, M.; Snaith, H. J. Observation and Mediation of the Presence of Metallic Lead in Organic-Inorganic Perovskite Films. ACS Appl. Mater. Interfaces 2015, 7, 13440-13444.

(47) Lindblad, R.; Bi, D.; Park, B. - W.; Oscarsson, J.; Gorgoi, M.; Siegbahn, H.; Odelius, M.; Johansson, E. M. J.; Rensmo, H. Electronic Structure of $\mathrm{TiO}_{2} / \mathrm{CH}_{3} \mathrm{NH}_{3} \mathrm{PbI}_{3}$ Perovskite Solar Cell Interfaces. J. Phys. Chem. Lett. 2014, 5, 648-653.

(48) Umebayashi, T.; Asai, K.; Kondo, T.; Nakao, A. Electronic Structures of Lead Iodide Based Low-Dimensional Crystal. Phys. Rev. B: Condens. Matter Mater. Phys. 2003, 67, 155405.

(49) Wang, B.; Xiao, X.; Chen, T. Perovskite Photovoltaics: a High Efficiency Newcomer to the Solar Cell Family. Nanoscale 2014, 6, 12287-12297.

(50) Schulz, P.; Edri, E.; Kirmayer, S.; Hodes, G.; Cahen, D.; Kahn, A. Interface Energetics in Organo-Metal Halide Perovskite-based Photovoltaic Cells. Energy Environ. Sci. 2014, 7, 1377-1381.

(51) Kahn, A. Fermi level, work function and vacuum level. Mater. Horiz. 2016, 3, 7-10.

(52) Endres, J.; Pelczer, I.; Rand, B. P.; Kahn, A. Determination of Energy Level Alignment within an Energy Cascade Organic Solar Cell. Chem. Mater. 2016, 28, 794-801.
(53) Correa Baena, J.-P.; Steier, L.; Tress, W.; Saliba, M.; Neutzner, S.; Matsui, T.; Giordano, F.; Jacobsson, T. J.; Kandada, A. R. S.; Zakeeruddin, S. M.; et al. Highly Efficient Planar Perovskite Solar Cells through Band Alignment Engineering. Energy Environ. Sci. 2015, 8, 2928-2934.

(54) Lopez, R.; Gomez, R. Band-Gap Energy Estimation from Diffuse Reflectance Measurements on Sol-Gel and Commercial $\mathrm{TiO}_{2}$ : a Comparative Study. J. Sol-Gel Sci. Technol. 2012, 61, 1-7.

(55) Toney, J. E. Photoluminescence Spectroscopy. Characterization of Materials; Wiley Online Library, 2002; DOI: 10.1002/ 0471266965.com058.

(56) Melitz, W.; Shen, J.; Kummel, A. C.; Lee, S. Kelvin Probe Force Microscopy and its Application. Surf. Sci. Rep. 2011, 66, 1-27.

(57) Lozac'h, M.; Ueda, S.; Liu, S.; Yoshikawa, H.; Liwen, S.; Wang, X.; Shen, B.; Sakoda, K.; Kobayashi, K.; Sumiya, M. Determination of the Surface Band Bending in $\operatorname{In}_{\mathrm{x}} \mathrm{Ga}_{1-\mathrm{x}} \mathrm{N}$ Films by Hard X-Ray Photoemission Spectroscopy. Sci. Technol. Adv. Mater. 2013, 14, 015007.

(58) Fan, H.; Yang, Z.; Ren, X.; Yin, M.; Gao, F.; Liu, S. Band Alignment of $\mathrm{TiO}_{2}$ /FTO Interface Determined by X-Ray Photoelectron Spectroscopy: Effect of Annealing. AIP Adv. 2016, 6, 015314.

(59) Philippe, B.; Park, B.-W.; Lindblad, R.; Oscarsson, J.; Ahmadi, S.; Johansson, E. M. J.; Rensmo, H. Chemical and Electronic Structure Characterization of Lead Halide Perovskites and Stability Behavior under Different Exposures - A Photoelectron Spectroscopy Investigation. Chem. Mater. 2015, 27, 1720-1731.

(60) Endres, J.; Egger, D. A.; Kulbak, M.; Kerner, R. A.; Zhao, L.; Silver, S. H.; Hodes, G.; Rand, B. P.; Cahen, D.; Kronik, L.; et al. Valence and Conduction Band Densities of States of Metal Halide Perovskites: A Combined Experimental-Theoretical Study. J. Phys. Chem. Lett. 2016, 7, 2722-2729. 